In their new brewery, near the railway station, the crushed malt is lifted from one floor to another by a series of cups revolving on a leathern band. The casing, which incloses the band, is full of floating malt dust while the revolution is going on, and on opening one of the doors of the casing a puff of maltdust is sent out into the room. Soon after the brewery was opened, a workman went with an undefended light to make some examination of the working of the leathern band, and on opening the door of the casing an explosion followed; not of a very serious character, but enough, I think, to throw the band out of gear. The cause of the explosion is evident; the rapid co nbustion of the fine malt dust with which the air puffed out into the room was charged.

Dr Böttinger died a few years since, but it would probably not be diff cult to get accurate details of the accident from Messrs. Allsopp and Sons.

Bowdon, December II

A. MACKENNAH

\section{Means of Dispersal}

IN his great work, "Insecta Maderensia," Mr. Wollaston remarks upon the great affinity in the coleopterous fauna of Madeira with that of Sicily, and in his "Coleoptera $\mathrm{H}$-speri. dum," on the northern character of that of the Cape Verde Isles. Mr. Andrew Murray also found that out of 275 Cape Verde species 9I were common to the Canaries and 8I to the Madeiran group. The last author would seem to rely on the efficacy of now submerged continents as a means of transmission between the two areas.

Towards the end of the fifteenth and commencement of the sixteenth century, the Poriuguese carried the sugar-cane from Sicily to Madeira and the Canaries. The means of introduction would probably be the same then as now; the young shoots of cane would be conveyed in boxes or baskets of earth from one locality to the other, as the writer orice carried young cane plants from Car Nicobar viâ Rangoon to Penang, and has seen the same arrive in the last locality from the. West Indies. There can be little doubt that many of these plants must have been carried from Sicily to the Atlantic Isles before a successful or sufficient introduction was made, and with the earth in which the plants were conveyed, many geodephagous and other coleoptera would find an enforced means of migration. The sugar-cane is also reported as having been introduced into Cyprus from Asia, and transplanted from there to Madeira, thus adding another link to the localities in which these coleopteral affinities have been detected.

It is not proposed that this was the sole, but only a probable means of the transmission of common form in the coleopteral faunas of these widely-separated districts. The number of causes which have been factors to the same in the past may be in an inverse ratio to our knowledge of them. W. L. DISTANT

\section{Supplementary Eyebrows}

I MET a gentleman a few days ago who has on either side of the forehead a suppletrentary eyebrow branching off from the superciliary ridge near the supra-orbital notch, and passing obliquely upwrerds and outwards fur about $\frac{8}{4}$ inch acro ss the forehead. Beneath these brows, which contain large and coarse hairs, are lines of soft down-like hair, one on either side occupying the usual position of the eyebrows. Since my attention was drawn to this subject I have noticed that many persons have a shorr secondary spur of hairs at the points indicated. Artists, I believe; have noticed this deviation frum the normal eyebrow-line, as we occasionally observe it in por raits of Puck and other mischievous sprites.

There is a spot about midway between the orbits in animals that I have examin d (namely, horses, dogs, and cats), whence the lines of halr-insertion into the skin radiate in various directions. If we consider the secondary eyebrows of man as a reversion to an ancestral type, we must conclude that our hairy progenitors also possessed such a radiating point of hair insertion upon their foreheads, and that the secondary eyebrows are only remnants of a hairy covering which originally enveloped the whole face.

Brighton

W. AINSLIE HOLLIS

\section{Diffusion or Cohesion Figures in Liquids}

With reference to the above, allow me to relate some experiments made several years ago, and easily repeated.

I. Take a tall precipitate slass, fill it with water, drop into it a piece of lump or refined sugar and four or five grains of common salt. Let the vessel remain quiet, so that when the sugar is dis. solved there may be different densities in the fluid from top to bottom. Then lightly touch the surface with a piece of lunar caustic (silver nitrate), and observe the figure which results.

2. The experiment may be repeated with sugar, diluted sulphuric acid, and barium chloride, the figures varying with the proportions of the ingredients used.

3. Take a common tumbler glass filled with water, dissolve in it half a tea-spoonful of common salt. Touch the surface of the solution with the point of a pen filled with ordinary black ink, and the characteristic figures are produced.

F.R.S.

Brighton, December 12

\section{Meteor}

AT 8h. 13m. ( \pm 2 n.) P.M. on December 9, a brilliant meteor passed from 32 Cameleopardalis $\left( \pm I^{\circ}\right)$ through $\mu$ Lyræ $\left( \pm 1^{\circ}\right)$, and disappeared about $6^{\circ}$ beyond ; time of passage, I. $6( \pm 3)$ sec.; mag., 8 (士 2) $\chi$ Lyræ; colour, emerald green; track, yellow, visible $\mathrm{I}$ second; seen from $5 \mathrm{I}^{\circ} 24^{\prime} 43^{\prime \prime} \mathrm{N}, \mathrm{2}^{\prime} \mathrm{I}^{\prime \prime} \mathrm{E}$. This may enable anorthern observer to fix the position.

Bromley, Kent

W. M. F. P.

$$
\text { ON THE CAUSATION OF SLEEP }
$$

THE last number of Pflïger's Archiv (vol. xv., p. 573) contains the following interesting note by Dr. Strümpell :-

"In the autumn of last year there was received into the medical clinik of Leipzig a youth, aged 16 , in whom various phenomena of anæsthesia gradually developed themselves to an extent which has very rarely been observed. The skin of the whole surface of the body was completely insensible, and that in respect to every kind of sensation. The most powerful electric current-a burning taper held to the skin-was not able to produce any pain or even a sensation of touch. Almost all the accessible parts of the mucous membrane of the body exhibited the same insensibility to pain. Also all those sensations which are classed together under the name of 'muscular sense,' were entirely absent. The patient, when his eyes were closed, could be carried about round the room, his limbs could be placed in the most inconvenient positions without his being in any way conscious of it. Even the feeling of muscular exhaustion was lost. In addition there came on also a complete loss of taste and smell, amaurosis of the left eye, and deafness of the right ear.

"In short, here was an individual whose only connection with the outer world was limited to two doors of sense-to his one (right) eye, and his one (left) ear. Moreover, both these remaining doors could at any time be easily closed, and in this way it was possible to inves* tigate the consequences of completely isolating the brain from all external stimulation through the senses. I have frequently made the following experiment, and often showed it to others :- If the patient's seeing eye was bandaged and his hearing ear was stopped, after a few (usually from two to three) minutes the expression of surprise and the uneasy movements which at first showed themselves ceased, the respiration became quiet and regular ; in fact the patient was sound asleep. Here, therefore, the possibility of artificially inducing sleep at any time in a person simply by withholding from the brain all stimulation by means of the senses was realised.

"The awakening of the patient was as interesting as the sending him to sleep. He could be awakened by an auditory stimulation, as, for example, by calling into his hearing ear or by visual stimulation, by allowing the stimulus of light to fall upon his seeing eye; but he could not be woke by any pushing or shaking. If he was left to himself he did eventually wake up of his own accord in course of the day, after the sleep had lasted many hours, the awakening being due, it might be, to intrinsic stimuli started in the brain, or it might be to slight external unavoidable stimuli acting through his still functional sense organs; and making themselves felt in consequence of the sensitiveness of the brain being increased during the repose of the sleep." 